\title{
Accuracy of noninvasive haemoglobin measurement by pulse oximetry depends on the type of infusion fluid
}

Christian Bergek, Joachim Zdolsek and Robert Hahn

Linköping University Post Print

\section{Tweet}

N.B.: When citing this work, cite the original article.

This is the pre-reviewed version of the following article:

Christian Bergek, Joachim Zdolsek and Robert Hahn, Accuracy of noninvasive haemoglobin measurement by pulse oximetry depends on the type of infusion fluid, 2012, European Journal of Anaesthesiology, (29), 12, 586-592.

which has been published in final form at:

http://dx.doi.org/10.1097/EJA.0b013e3283592733

Copyright: Lippincott, Williams \& Wilkins / Wiley-Blackwell http://www.lww.com/

Postprint available at: Linköping University Electronic Press http://urn.kb.se/resolve?urn=urn:nbn:se:liu:diva-86624 


\section{Accuracy of non-invasive haemoglobin $(\mathrm{SpHb})$ depends on the type of infusion fluid}

Christian Bergek, Joachim H. Zdolsek and Robert G. Hahn

Section for Anaesthesia,

Faculty of Health Sciences,

Linköping University, Linköping, Sweden

Short title: Pulse oximetry $\mathrm{Hb}$ and infusion fluids

\section{ADDRESS CORRESPONDENCE TO:}

Robert Hahn MD, PhD

Department of Anaesthesia

Linköping University Hospital

58585 Linköping, Sweden

Phone: +46739660972

Fax: +46855024671

E-mail: r.hahn@telia.com 


\section{Abstract}

Context Measurement of blood haemoglobin $(\mathrm{Hb})$ concentration by pulse oximetry $(\mathrm{SpHb})$ could be of value to determine when erythrocytes should be transfused during surgery, but the effect of infusion fluids on the results is unclear.

Objective To study the effect of crystalloid and colloid fluid on the accuracy (bias) and precision of $\mathrm{SpHb}$ to indicate the venous $\mathrm{Hb}$ concentration in volunteers.

Design Open interventional crossover study.

Setting Single university hospital.

Subjects Ten male volunteers aged 18-28 (mean, 22) years.

Interventions Each volunteer underwent three infusion experiments on separate days and in random order. The infusions were Ringer's acetate $\left(20 \mathrm{ml} \mathrm{kg}^{-1}\right)$, hydroxyethyl starch 130/0.4 (10 $\left.\mathrm{ml} \mathrm{kg}^{-1}\right)$ and a combination of both.

Results At the end of the infusions of Ringer's acetate, $\mathrm{SpHb}$ had decreased more than $\mathrm{Hb}$ (15 versus $8 \% ; P<0.005 ; \mathrm{n}=10)$ while starch solution decreased $\mathrm{SpHb}$ less than $\mathrm{Hb}(7$ versus $11 \% ; P<0.02 ; \mathrm{n}=20)$. The same differences were seen when the fluids were infused separately and when they were combined. The overall difference between all 956 pairs of $\mathrm{SpHb}$ and $\mathrm{Hb}$ (the bias) averaged only $-0.7 \mathrm{~g} \mathrm{l}^{-1}$ while the $95 \%$ prediction interval was wide, ranging from [-24.9] to $23.7 \mathrm{~g}^{-1}$. Besides the choice infusion fluid, the bias was strongly dependent on the volunteer (each factor $P<0.001$ ).

Conclusion The bias of measuring $\mathrm{Hb}$ by pulse oximetry is dependent on whether a crystalloid or a colloid fluid is infused.

Trial registration ClinicalTrials identifier: NCT01195025 


\section{Introduction}

Measurement of haemoglobin concentration $(\mathrm{Hb})$ is usually made in blood sampled from a cubital vein. During surgery, $\mathrm{Hb}$ is essential for decisions about whether to transfuse erythrocytes. Therefore, sporadic measurement of $\mathrm{Hb}$ is performed during major surgery as a guide to when transfusion should be initiated.

$\mathrm{The} \mathrm{Hb}$ concentration can also be inferred non-invasively and continuously by multi-wavelength pulse $\mathrm{CO}$-oximetry $(\mathrm{SpHb})$, which might serve as an attractive alternative to invasive sampling. This recently reviewed technique ${ }^{1}$ has been used in studies involving volunteers and surgery, with varying conclusions about accuracy and precision. ${ }^{2-11}$ However, little is known about how $\mathrm{SpHb}$ reacts to specific procedures performed during surgery, such as intravenous infusion of crystalloid and colloid fluid. There is some evidence that $\mathrm{SpHb}$ changes more than $\mathrm{Hb}$ during volume loading with Ringer's acetate ${ }^{7}$ but no evaluation of the accuracy of $\mathrm{SpHb}$ during administration of colloid fluid has been performed.

In the present study, we investigate the reliability (accuracy and precision) of $\mathrm{SpHb}$ to measure $\mathrm{Hb}$ during and after infusion of Ringer's acetate and $6 \%$ hydroxyethyl starch 130/0.4 in volunteers. These fluids were given separately and in combination, as crystalloid and colloid fluids are often administered together in major surgery. The hypothesis was that both infusions would change the accuracy of $\mathrm{SpHb}$ as a measure of $\mathrm{Hb}$. The perfusion index (PI) was also recorded, because $\mathrm{SpHb}$ seems to provide lower values when PI is low. ${ }^{2}$ 


\section{Methods}

Ten male volunteers aged between 18 to 28 (mean, 22) years and with a body weight between 65-101 (mean, 79) $\mathrm{kg}$ underwent three infusion experiments between August and December 2010. The protocol was part of a project evaluating the blood volume expanding effects of mixed fluid therapy (starch solution followed by crystalloid solution). The study was approved by the Regional Ethics Committee, Karolinska Institutet, 17177 Stockholm, Sweden, on September 18, 2009 (Dnr 2009/1091-31/2; Chairperson Ulla Erlandsson) and registered at ClincalTrials by identifier NCT01195025. Each volunteer gave his consent for participation after being informed about the study both orally and in writing.

The experiments started between 7:30 and 8:30 AM in the Department of Intensive Care at Linköping University Hospital. The volunteers had fasted since midnight but were allowed to eat one sandwich and drink one glass $(200 \mathrm{ml})$ of liquid at 6 AM. When they arrived at the department, they rested on a bed below an OPN Thermal Ceiling radiant warmer (Aragon Medical, River Vale, NJ, USA) placed about $1 \mathrm{~m}$ above them. The heat was adjusted to achieve maximum comfort. A cannula was placed in the antecubital vein of each arm to infuse fluid and sample blood, respectively. Thirty minutes of rest to reach haemodynamic steady state was allowed before the experiments started.

\section{Infusions}

Each volunteer underwent the following three experiments in random order, separated by at least 7 days (Fig. 1):

A. Infusion of Ringer's acetate, $20 \mathrm{ml} \mathrm{kg}^{-1}$, over 30 minutes ( 2 received $25 \mathrm{ml} \mathrm{kg}^{-1}$ ).

B. Infusion of starch, $10 \mathrm{ml} \mathrm{kg}^{-1}$, over 30 minutes.

C. Infusion of combined starch and Ringers' acetate; $10 \mathrm{ml} \mathrm{kg}^{-1}$ of starch was infused between 0 and 30 minutes, followed by $20 \mathrm{ml} \mathrm{kg}^{-1}$ of Ringer's between 105 and 135 minutes.

The crystalloid fluid was acetated Ringer's (Baxter, Deerfield, IL; sodium 130, 
chloride 110 , acetate 30 , potassium 4 , calcium 2, and magnesium $1 \mathrm{mmol} / \mathrm{l}$ ).

The colloid was hydroxyethyl starch 6\% 130/0.4 (Voluven, Fresenius Kabi; Bad Homburg, Germany; sodium 154, chloride $154 \mathrm{mmol} / \mathrm{l})$.

The volume of colloid was chosen to correspond to previous work using albumin. ${ }^{12}$ The infused volume of Ringer's acetate has usually been $25 \mathrm{ml} / \mathrm{kg}$ in studies of plasma volume expansion in healthy volunteers ${ }^{13}$ but it was slightly reduced here to avoid excessive cardiovascular strain in the combined experiment.

The fluids were administered at room temperature $\left(23^{\circ} \mathrm{C}\right)$ via infusion pumps (Volumat MC Agilia, Fresenius Kabi).

\section{Measurements}

Venous blood (3-4 $\mathrm{ml})$ was withdrawn from the antecubital venous cannula, using a vacuum tube, without stasis of the upper arm The baseline sample was drawn in duplicate, and the mean was used in further calculations. A small volume of blood was drawn before each sampling, and the volume replaced by $2 \mathrm{ml}$ of $0.9 \%$ saline to prevent clotting. The venous blood $\mathrm{Hb}$ was measured on a Cell-Dyn Sapphire hematology cell counter (Abbot Diagnostics, Abbot Park, IL, USA). Duplicate samples drawn at baseline ensured a coefficient of variation of $1.2 \%$.

The sampling intensity varied slightly depending on the length of the experiment. In the Ringer experiment, blood was drawn every $5^{\text {th }}$ min up to $60 \mathrm{~min}$, and thereafter every $10^{\text {th }} \mathrm{min}$ up to $180 \mathrm{~min}$. The same protocol was followed when starch alone was infused, but the follow-up continued with blood sampling every $30^{\text {th }}$ min up to $420 \mathrm{~min}$. In the combined experiment, the higher sampling intensity (every $5^{\text {th }} \mathrm{min}$ ) was re-instituted for 60 min when the second infusion started.

$\mathrm{SpHb}$ and PI were measured by the Radical 7 pulse CO-oximeter (Masimo Corp., Irvine, CA, USA) which uses light of multiple wavelengths and also advanced filtering and processing of the signals to yield theses values ${ }^{1}$. A single-use patient adhesive sensor of type R2-25a was attached to the middle finger of one hand. The venous samples were drawn from the same arm and the infusions were given in the other. The software delivered by the manufacturer was SET V7.6.0.1. The data were averaged every 8 seconds.

PI is a measure of the pulse amplitude in the finger and is obtained as the ratio 
between the pulsatile and the non-pulsatile absorption of infrared light. For each invasive blood sample, we recorded the SpHb and PI displayed on the front of the Radical 7. Haemodynamic monitoring also included non-invasive blood pressure and heart rate.

\section{Statistics}

Data are given as the median and $25^{\text {th }}-75^{\text {th }}$ percentiles, except where noted. Differences between paired data were evaluated by the Wilcoxon matched-pair test, and differences between unpaired samples by the Mann-Whitney $U$ test. Comparisons between three groups were made by applying the Kruskal-Wallis test.

The influence of several factors on a continuous variable was tested by two-way ANOVA, and the relationship between parameters by simple and multiple linear regression (where $r=$ correlation coefficient).

The accuracy (bias) of using $\mathrm{SpHb}$ to indicate $\mathrm{Hb}$ was expressed as the absolute or relative difference between the paired measurements, the latter being:

$$
\text { Relative difference }(\%)=\frac{\mathrm{SpHb}-\mathrm{Hb}}{(\mathrm{Hb}+\mathrm{SpHb}) / 2} \bullet 100
$$

The precision of using $\mathrm{SpHb}$ to indicate $\mathrm{Hb}$ was expressed the absolute value of the relative difference between the paired measurements.

The 95\% prediction interval for the absolute difference between $\mathrm{SpHb}$ and $\mathrm{Hb}$ is the range in which $95 \%$ of the $\mathrm{SpHb}-\mathrm{Hb}$ differences are to be found.

The accuracy and precision of $\mathrm{SpHb}$ to indicate $\mathrm{Hb}$ is also illustrated by BlandAltman plots. Calculations were considered statistically significant if $P<0.05$. 


\section{Results}

All 10 volunteers completed the study, which comprised 30 experiments altogether (Fig.

1). Baseline data are shown in Table 1.

\section{Haemoglobin changes during infusion}

At the end of the first infusion of Ringer's acetate, $\mathrm{SpHb}$ had decreased more than $\mathrm{Hb}$ (15\% versus $8 \% ; P<0.005 ; \mathrm{n}=10$; Fig. 2 A).

At the end of the infusions of starch, $\mathrm{SpHb}$ had decreased less than $\mathrm{Hb}(7 \%$ versus $11 \% ; P<0.02$; $\mathrm{n}=20$; Fig. 2 B-C).

At the end of the infusion of Ringer's acetate in the combined experiment, $\mathrm{SpHb}$ had again decreased more than $\mathrm{Hb}(11 \%$ versus $5 \%$; $P<0.03$; $\mathrm{n}=10$; Fig. $2 \mathrm{C})$.

\section{Differences between SpHb and Hb}

$\mathrm{SpHb}$ tended to be lower than $\mathrm{Hb}$ at baseline (median $136.5 \mathrm{~g}^{-1}$ versus $144 \mathrm{~g} \mathrm{l}^{-1} ; P=0.07$; $\mathrm{n}=30$ ) which yielded a bias of $-3.8 \%$ and a precision of $6.6 \%$.

Infusion of Ringer's acetate increased the bias by $7.0(2.5-11.1) \%(P<0.04$, median, $25^{\text {th }}-75^{\text {th }}$ percentile range) while starch decreased the bias by $4.3(0.9-7.2) \%(P<$ $0.02 ; \mathrm{n}=20$; Table 2).

The precision had become $4.6 \%([-1.7]-6.1 \%)$ poorer at the end of the Ringer infusions $(P<0.02)$ while starch did not affect the precision, the median change being $0.8 \%([-3.5]-3.7 \%)$ (not statistically significant, Table 2).

The mean difference between all 956 pairs of $\mathrm{SpHb}$ and $\mathrm{Hb}$ (the bias) was $-0.7 \mathrm{~g} \mathrm{l}^{-}$

1. The median $\left(25^{\text {th }}-75\right.$ percentiles $)$ were $-2([-10]-8) \mathrm{g}^{-1}$ which corresponds to an accuracy of -0.8 ([-7.5]-5.9)\% and a median precision of 6.6 (3.1-10.7)\% (Table 2). The $95 \%$ prediction interval for the $\mathrm{SpHb}-\mathrm{Hb}$ difference ranged from -24.9 to $23.7 \mathrm{~g} \mathrm{l}^{-1}$ (Figs. $3,4)$.

Two-way ANOVA showed that the bias was dependent on the infusion experiment, 
but also strongly dependent on the volunteer (each factor $P<0.001$; Table 3 ).

The difference between $\mathrm{SpHb}$ and $\mathrm{Hb}$ became more positive (so that $\mathrm{SpHb}>\mathrm{Hb}$ ) with lower $\mathrm{Hb}$ concentrations ( $\mathrm{r}=0.42, P<0.001$; Fig. 4).

\section{Perfusion index}

PI was 7.0 (4.3-9.2)\% at baseline. The Ringer infusions decreased PI from (median) $7.0(4.4-11.0) \%$ to $2.5(1.3-6.4) \%$ and the starch infusion from $5.4(5.0-8.1) \%$ to 3.0 (1.9-6.1)\% (repeated-measures ANOVA $P<0.01$ and 0.02, respectively; Table 2).

The SpHb-Hb difference increased with a higher PI. Thus, a median PI above $7.0 \%$ during the experiments was associated with a positive bias whereas for $\mathrm{PI} \leq 7.0 \%$ the average bias was negative (Table 4). This was explained by that $\mathrm{SpHb}$ but not $\mathrm{Hb}$ increased with PI (Fig. 5). Multiple regression analysis showed that the effect of PI on the bias was statistically independent from the opposite effect of $\mathrm{Hb}$ per se that is illustrated in Fig. 4 (combined factors; $\mathrm{r}=0.49 ; P<0.001$ ). 


\section{Discussion}

The results show that the accuracy of non-invasive $\mathrm{SpHb}$ is dependent on the type of infusion fluid administered. Starch caused $\mathrm{SpHb}$ to decrease much less than $\mathrm{Hb}$, and the difference was long lasting. On the other hand, when infusing Ringer's acetate, the decrease in $\mathrm{SpHb}$ was greater and more transient. Both of these effects could also be discerned in the combined experiment (Fig. 2).

Other factors were also found to affect the bias of the $\mathrm{SpHb}$ measurement. In addition to the choice of infusion fluid, the between-subject variation was important (Table 3). A low $\mathrm{Hb}$ concentration per se promoted a more positive bias, which means that $\mathrm{SpHb}$ overestimated $\mathrm{Hb}$ when a correct indication could be clinically important. Moreover, $\mathrm{SpHb}$ increased slightly with $\mathrm{PI}$, which confirms previous findings. ${ }^{2}$ Other authors have also reported a positive $\mathrm{SpHb}-\mathrm{Hb}$ difference when PI is below $2^{3,9}$ while our findings propose that the same relationship exists also when PI exceeds 7 (Table 4).

Starch administration, low $\mathrm{Hb}$ and high PI were all factors that promoted a more positive $\mathrm{SpHb}-\mathrm{Hb}$ difference, thereby acting to mislead the clinician with regard to the need for erythrocyte transfusion. The reasons for inconsistency of the $\mathrm{SpHb}$ measurement are unclear. One hypothesis is that our fluid load might have disturbed this balance by expanding the vessels and also by diluting $\mathrm{Hb}$ differently in arterioles, capillaries, and veins. ${ }^{15}$ Faster disappearance of crystalloids than colloids from the bloodstream ${ }^{16,17}$ promotes tissue oedema, which could diminish the relative strength of the pulsatile part of the signal by affecting the background noise. The time-course of the negative $\mathrm{SpHb}$ $\mathrm{Hb}$ difference when acetated Ringer's is infused (Fig. 2A) is consistent with findings that the net movement of fluid from plasma to the interstitium in the arm is reversed within 2.5 minutes after the end of a brisk infusion. ${ }^{17}$ In contrast, accumulation of infused fluid in peripheral tissues is more long-lasting when the whole body is studied. ${ }^{13}$ The opposite change of the $\mathrm{SpH}-\mathrm{Hb}$ difference in response to starch might possibly be due to overlapping of physical absorbance characteristics of starch and Hb. Experimental studies investigating the microvasculature in combination with the spectrophotometry and the optical physics may give answers to the open questions in this study. 
The bias calculated from a large number of paired measurements is usually quite small in studies using the $\mathrm{SpHb}$ technology. The bias when infusing crystalloid fluid was $-1.6 \%$ in a previous $\operatorname{study}^{7}$, and in blood withdrawal followed by crystalloid fluid the figure averaged $-1.5 \mathrm{~g}^{-1} .9$ In spine surgery, the bias was $-2.6 \mathrm{~g} \mathrm{l}^{-1},{ }^{2}-3 \mathrm{~g} \mathrm{l}^{-1},{ }^{10}$ and $-12.7 \mathrm{~g}$ $1^{-1}{ }^{11}$ Other data from the perioperative setting were $-0.2 \mathrm{~g} \mathrm{l}^{-1}, 8 \mathrm{-2.9} \mathrm{g} \mathrm{l}^{-1}, 4$ and $0 .^{5}$ Extreme bias include -13 to $-17 \mathrm{~g} \mathrm{l}^{-1}$ in cardiac intensive care ${ }^{3}$ and $-18 \mathrm{~g} \mathrm{l}^{-1}$ in emergency care. ${ }^{6}$ In all these studies the $\mathrm{SpHb}$ showed a lower mean value than $\mathrm{Hb}$, thereby the negative bias.

In contrast, poor precision is a problem. According to published graphs and charts, the $95 \%$ prediction interval for the $\mathrm{SpHb}-\mathrm{Hb}$ difference has been $40 \mathrm{~g} \mathrm{l}^{-1}, 4,9,1040$ $50 \mathrm{~g} \mathrm{l}^{-1,8} 67-80 \mathrm{~g} \mathrm{l}^{-1}, 2,3,11$ and $110 \mathrm{~g} \mathrm{l}^{-1}{ }^{6}$ In the present study, the range was almost $50 \mathrm{~g} \mathrm{l}^{-1}$. Some of the wide variability in the $\mathrm{SpHb}-\mathrm{Hb}$ difference in previous studies might well be caused by the fluid therapy used when data was collected.

The $\mathrm{SpHb}$ difference at baseline differed slightly between the three experiments (Table 2). Small variations can be due to the state of hydration of the volunteers, as the Radical 7 measures SpHb in arterial blood while the sampled blood was venous. The arteriovenous $\mathrm{Hb}$ difference has been reported to be $-1.8 \mathrm{~g}^{-1}$ of non-fasting volunteers in the afternoon ${ }^{18}$, but amounted only to $-0.3 \mathrm{~g}^{-1}$ in semi-fasting male volunteers studied in the morning. ${ }^{19}$ The gradient might even become zero or slightly positive after an overnight fast ${ }^{20}$ as evidence of fluid transport away from the arm. The Radical 7 can be set to reflect $\mathrm{SpHb}$ in venous blood, which simply makes it to report 0.7-1.0 $\mathrm{g} \mathrm{l}^{-1}$ higher values. This possibility was not used in the present study as the arteriovenous $\mathrm{Hb}$ difference was likely to be close to zero at baseline. However, the true difference was probably increased to approximately $-1 \mathrm{~g}^{-1}$ during the infusion of Ringer's acetate ${ }^{19}$. The arteriovenous $\mathrm{Hb}$ difference induced by the infusion can therefore only explain a fraction of the difference between $\mathrm{SpHb}$ and $\mathrm{Hb}$ at the end of the Ringer's infusions, which amounted to almost $-11 \mathrm{~g} \mathrm{l}^{-1}$.

In a previous report PI decreased when Ringer's acetate was infused ${ }^{7}$, and the same change was seen in the present study. This effect is surprising, since PI is an index of blood flow that is expected to increase as the result of volume loading. As this did not occur, we have suspected that the oedema caused by the infusion had decreased the ratio between pulsatile and non-pulsatile flow. However, this cannot be correct, since the PI 
also decreased when starch was infused, despite the fact that colloid fluids are not deposited extravascularly early on during an infusion. ${ }^{16}$ On the other hand, the fluids infused at room temperature cooled the body and thereby resulted in vasoconstriction and less perfusion. But since all fluids were of the same temperature, and the amount of Ringer's was twice that of starch, the cooling effect would then logically be twice as large in the Ringer's experiment. However, the fall in PI was much greater when infusing starch. Therefore, temperature offers no satisfying explanation for the change in PI.

Limitations include that the infusions were administered to normovolaemic subjects, which is often not the case in clinical practice. The difference between the $\mathrm{SpHb}$ and $\mathrm{Hb}$ might be different when a hypovolaemic patient is infused. Moreover, differences between healthy volunteers may not completely reflect the situation in anaesthetized patients. Moreover, only male volunteers were studied as females have difficult to void in the lying position.

In conclusion, the $\mathrm{SpHb}$ changes in response to intravenous fluid differ depending on whether a crystalloid (Ringer's acetate) or colloid fluid (starch solution) is given. Starch administration, low blood $\mathrm{Hb}$ concentration and high perfusion index are all factors that promote a positive $\mathrm{SpHb}-\mathrm{Hb}$ difference, which can mislead the clinician to underestimate the need for erythrocyte transfusions. On the other hand, infusion of Ringer's solution, a high blood $\mathrm{Hb}$ and a low perfusion index act to exaggerate the need for transfusing erythrocytes.

Acknowledgements: Assistance with the study was given by nurse anaesthetist Susanne Öster. The Intensive Care Unit in Linköping University Hospital provided us with room for the experiments. Financial support was received from Stockholm City and Östergötland County Council. Robert Hahn has provided lectures about fluid therapy sponsored by Baxter Medical Corp. There are no other conflicts of interest. 


\section{References}

1. Shamir MY, Avramovich A, Smaka T. The current status of continuous noninvasive measurement of total, carboxy, and methemoglobin concentration. Anesth Analg 2012; 114: 972-978.

2. Miller RD, Ward TA, Shiboski SC, Cohen NH. A comparison of three methods of hemoglobin monitoring in patients undergoing spine surgery. Anesth Analg 2011; 112: $858-863$.

3. Nguyen B-V, Vincent J-L, Nowak E, et al. The accuracy of noninvasive hemoglobin measurement by multiwavelength pulse oximetry after cardiac surgery. Anesth Analg 2011; 113: 1052-1057.

4. Causey MW, Miller S, Foster A, Beekley A, Zenger D, Martin M. Validation of noninvasive hemoglobin measurements using the Masimo Radical-7 SpHb Station. Am J Surg 2011; 201: 592-598.

5. Frasca D, Dahyot-Fizelier C, Catherine K, Levrat Q, Debaene B, Mimoz O. Accuracy of a continuous noninvasive hemoglobin monitor in intensive care unit patients. Crit Care Med 2011; 39: 2277-2282.

6. Gayat E, Bodin A, Sportiello C, et al. Performance evaluation of a noninvasive hemoglobin monitoring device. Ann Emerg Med 2011; 57: 330-333.

7. Hahn RG, Li Y, Zdolsek J. Non-invasive monitoring of blood haemoglobin for analysis of fluid volume kinetics. Acta Anaesthesiol Scand 2010; 54: 1233-1240.

8. Lamhaut L, Apriotesei R, Combes X, Lejay M, Carli P, Vivien B. Comparison of the accuracy of noninvasive hemoglobin monitoring by spectrophotometry $(\mathrm{SpHb})$ and HemoCue ${ }^{\circledR}$ with automated laboratory hemoglobin measurement. Anesthesiology 2011; 115: 548-554.

9. Macknet MR, Allard M, Applegate RL, Rook J. The accuracy of noninvasive and continuous total hemoglobin measurement by pulse CO-oximetry in human subjects undergoing hemodilution. Anesth Analg 2010; 111: 1424-1426.

10. Berkow L, Rotolo S, Mirski E. Continuous noninvasive hemoglobin monitoring 
during complex spine surgery. Anesth Analg 2011; 113: 1396-1402.

11. Colquhoun DA, Forkin KT, Durieux ME, Thiele RH. Ability of the Masimo pulse CO-Oximeter to detect changes in hemoglobin. J Clin Monit Comput 2012; 26: 6973.

12. Hedin A, Hahn RG. Volume expansion and plasma protein clearance during intravenous infusion of 5\% albumin and autologous plasma. Clin Sci 2005; 106: 217-224.

13. Drobin D, Hahn RG. Kinetics of isotonic and hypertonic plasma volume expanders. Anesthesiology 2002; 96: 1371-1380.

14. Nadler SB, Hidalgo JU, Bloch T. Prediction of blood volume in normal human adults. Surgery 1962; 51: 224-232.

15. Naftalovich R, Naftalovich D. Error in noninvasive spectrophotometric measurement of blood hemoglobin concentration under conditions of blood loss. Med Hypotheses 2011; 77: 665-667.

16. Ueyama H, He YL, Tanigami H, Mashimo T, Yoshiya I. Effects of crystalloid and colloid preload on blood volume in the parturient undergoing spinal anesthesia for elective Cesarean section. Anesthesiology 1999; 91: 1571-1576.

17. McIlroy DR, Kharasch ED. Acute intravascular volume expansion with rapidly administered crystalloid or colloid in the setting of moderate hypovolemia. Anesth Analg 2003; 96: 1572-1577.

18. Yang Z-W, Yang S-H, Chen L, Qu J, Zhu J, Tang Z. Comparison of blood counts in venous, fingertip and arterial blood and their measurement variation. Clin Lab Haem 2001; 23: 155-159.

19. Svensen CH, Rodhe PM, Olsson J, Børsheim E, Aarsland A, Hahn RG. Arteriovenous differences in plasma dilution and the distribution kinetics of lactated ringer's solution. Anesth Analg 2009; 108: 128-133.

20. Hahn RG, Lindahl CC, Drobin D. Volume kinetics of acetated Ringer's solution during experimental spinal anaesthesia. Acta Anaesthesiol Scand 2011; 55: 987994. 


\section{Table 1}

Data on volunteers, baseline values.

\begin{tabular}{|l|c|c|c|c|}
\hline Parameter & & Median & SD & $25-75 \%$ percentiles \\
\hline Age (years) & 10 & 21.0 & 3.4 & $19.0-23.8$ \\
Weight (kg) & 10 & 80.0 & 10.4 & $73.8-83.2$ \\
Length (cm) & 10 & 183.5 & 5.5 & $180.8-187.0$ \\
Body mass index $\left(\mathrm{kg} \mathrm{m}^{-2}\right)$ & 10 & 23.4 & 3.2 & $21.9-25.1$ \\
Blood volume (litre)* & 10 & 5.4 & 0.4 & $5.2-5.7$ \\
Initial Hb $\left(\mathrm{g} \mathrm{l}^{-1}\right)$ & 30 & 142.0 & 5.6 & $138.5-146.0$ \\
Initial SpHb $\left(\mathrm{g} \mathrm{l}^{-1}\right)$ & 30 & 136.5 & 9.9 & $130.0-146.5$ \\
\hline
\end{tabular}

* Blood volume was estimated according to $\operatorname{Nadler}^{14}: \mathrm{BV}=0.03219$ weight $(\mathrm{kg})+0.3669$ length $^{3}(\mathrm{~m})+0.6041$ 


\section{Table 2}

The non-invasive $\mathrm{Hb}(\mathrm{SpHb})$ and invasive venous $\mathrm{Hb}$ concentrations and the accuracy and precision of $\mathrm{SpHb}$ to predict invasive $\mathrm{Hb}$ in the course of the three infusion experiments. The perfusion index is also shown.

\begin{tabular}{|l|c|c|c|c|c|}
\hline Fluid & SpHb $\left(\mathrm{g} \mathrm{l}^{-1}\right)$ & $\mathrm{Hb}\left(\mathrm{g} \mathrm{l}^{-1}\right)$ & $\begin{array}{c}\text { Accuracy of SpHb } \\
\text { (relative difference, \%) }\end{array}$ & $\begin{array}{c}\text { Precision of } \\
\text { SpHb } \\
\text { (absolute relative } \\
\text { difference, \%) }\end{array}$ & $\begin{array}{c}\text { Perfusion } \\
\text { index (PI) } \\
\%\end{array}$ \\
\hline Ringer's acetate & & & & & \\
$\quad$ Start of infusion & $136.1(6.6)$ & $141.8(3.3)$ & $-4.1([-8.2]-[-2.5])$ & $4.8(3.2-8.2)$ & $5.4(5.0-8.1)$ \\
End of infusion & $119.6(12.6)$ & $128.6(5.0)$ & $-8.8([-14.8]-[-5.0])$ & $8.8(5.0-14.8)$ & $3.0(1.9-6.1)$ \\
End of test & $130.0(12.6)$ & $137.5(6.6)$ & $-7.6([-15.7]-3.1)$ & $9.1(6.2-15.7)$ & $4.8(3.3-7.1)$ \\
Entire experiment & $127.5(12.7)$ & $134.6(6.4)$ & $-5.3([-10.4]-1.5)$ & $7.9(3.2-11.5)$ & $4.6(2.5-7.8)$ \\
\hline & & & & & \\
\hline Starch & $135.4(9.0)$ & $143.2(8.0)$ & $-6.1([-10.9]-[-3.0])$ & $7.4(4.4-11.5)$ & $7.0(4.4-11.0)$ \\
Start of infusion & $123.5(5.2)$ & $126.7(6.3)$ & $-0.4([-10.0]-2.4)$ & $4.8(0.8-10.0)$ & $2.5(1.3-6.4)$ \\
End of infusion & $137.7(9.5)$ & $140.9(7.3)$ & $-2.3([-4.9]-3.3)$ & $4.0(3.3-7.1)$ & $4.4(3.1-5.3)$ \\
End of test & $131.9(8.5)$ & $133.0(7.8)$ & $0.0([-6.8]-4.6)$ & $5.5(2.5-8.8)$ & $5.1(3.3-7.8)$ \\
Entire experiment & & & & & \\
\hline & & & & & \\
\hline Starch+Ringer's acetate & $143.4(12.1)$ & $141.4(4.7)$ & $0.7([-6.2]-9.6)$ & $9.2(1.7-10.3)$ & $7.9(4.3-9.5)$ \\
Start of starch infusion & $132.7(11.6)$ & $124.2(4.2)$ & $5.2([-1.6]-14.8)$ & $5.7(3.9-14.8)$ & $3.0(2.0-6.5)$ \\
End of starch infusion & $137.3(10.6)$ & $130.3(5.6)$ & $5.8([-3.2]-13.1)$ & $7.5(4.7-13.1)$ & $6.0(4.2-6.9)$ \\
Start of Ringer infusion & $120.8(11.1)$ & $123.2(5.6)$ & $-5.0([-8.6]-7.6)$ & $8.4(6.7-14.4)$ & $2.6(1.5-5.3)$ \\
End of Ringer infusion & $133.9(9.2)$ & $134.0(6.0)$ & $2.9([-4.5]-7.8)$ & $6.3(3.6-8.7)$ & $3.2(2.3-4.4)$ \\
End of test & $131.9(12.3)$ & $128.1(6.5)$ & $1.5([-4.9]-10.9)$ & $5.7(2.2-10.3)$ & $4.8(2.8-7.6)$ \\
Entire experiment & & & & & \\
\hline
\end{tabular}

Data are the mean (SD) or the median and $25^{\text {th }}-75^{\text {th }}$ percentiles.

Relative difference $(\%)=\frac{\mathrm{SpHb}-\mathrm{Hb}}{(\mathrm{Hb}+\mathrm{SpHb}) / 2} \bullet 100$ 


\section{Table 3}

The accuracy (bias) of $\mathrm{SpHb}$ in indicating invasive $\mathrm{Hb}$ concentration during infusion experiments, expressed as the mean relative difference for all data in each of 10 volunteers.

\begin{tabular}{cccccc}
\hline $\begin{array}{c}\text { Volunteer } \\
\text { n:o }\end{array}$ & $\begin{array}{c}\text { Body weight } \\
(\mathrm{kg})\end{array}$ & \multicolumn{5}{c}{ Accuracy } & (relative difference, \%) & All three \\
& & & & & \\
Ringer's & Starch & Starch+ Ringer's & experiments \\
\hline 1 & 86 & -10.0 & -0.5 & 13.9 & 3.0 \\
2 & 82 & -12.1 & -11.5 & -5.2 & -9.0 \\
3 & 73 & -4.6 & 4.8 & -3.7 & -1.2 \\
4 & 79 & -22.1 & -8.9 & -8.4 & -12.2 \\
5 & 75 & -7.5 & -4.9 & 7.1 & -0.7 \\
6 & 101 & -5.1 & -0.7 & -1.4 & -2.1 \\
7 & 83 & -1.2 & 7.0 & -4.4 & 0.1 \\
8 & 80 & 0.05 & 6.2 & 16.3 & 8.8 \\
9 & 66 & 12.9 & -3.2 & 11.1 & 9.1 \\
10 & 66 & -7.6 & -3.8 & 0.4 & -3.1 \\
& & & & & \\
\hline
\end{tabular}

Data are the mean for one experiment.

Relative difference $(\%)=\frac{\mathrm{SpHb}-\mathrm{Hb}}{(\mathrm{Hb}+\mathrm{SpHb}) / 2} \bullet 100$ 


\section{Table 4}

Differences in the accuracy (bias) and precision of non-invasive $\mathrm{SpHb}$ in indicating invasive $\mathrm{Hb}$ during infusion experiments in 10 volunteers, depending on the perfusion index.

\begin{tabular}{|c|c|c|c|c|}
\hline \multirow[t]{2}{*}{ Parameter } & \multicolumn{3}{|c|}{ Perfusion index $(\%$, range $)$} & \multirow{2}{*}{$\begin{array}{c}\text { Kruskal-Wallis } \\
\text { test }\end{array}$} \\
\hline & $\leq 2$ & $2-7$ & $\geq 7$ & \\
\hline$N$ & 105 & 535 & 312 & \\
\hline $\mathrm{Hb}\left(\mathrm{g} \mathrm{l}^{-1}\right)$ & $130(124-135)$ & $131(126-137)$ & $132(126-136)$ & Not significant \\
\hline $\mathrm{SpHb}\left(\mathrm{g} \mathrm{l}^{-1}\right)$ & $125(120-131)$ & $129(123-137)$ & $133(125-144)$ & $P<0.0001$ \\
\hline $\mathrm{SpHb}-\mathrm{Hb}\left(\mathrm{g} \mathrm{l}^{-1}\right)$ & $-7([-12]-0)$ & $-3([-10]-4)$ & $3.5([-6]-13)$ & $P<0.0001$ \\
\hline Relative difference $(\%)$ & $-5.3([-9.2]-0.0)$ & $-2.4([-7.8]-3.4)$ & $2.4([-4.8]-9.6)$ & $P<0.0001$ \\
\hline $\begin{array}{l}\text { Absolute relative } \\
\text { difference }(\%)\end{array}$ & $7.4(4.8-10.1)$ & $6.1(3.0-10.4)$ & $8.4(3.6-12.4)$ & $P<0.0001$ \\
\hline
\end{tabular}

Data are the median and $25^{\text {th }}-75^{\text {th }}$ percentiles.

Relative difference $(\%)=\frac{\mathrm{SpHb}-\mathrm{Hb}}{(\mathrm{Hb}+\mathrm{SpHb}) / 2} \bullet 100$ 


\section{Legends for figures}

\section{Fig. 1.}

Flowchart describing the three parts of the study.

\section{Fig. 2.}

Change in $\mathrm{Hb}$ (red) and $\mathrm{SpHb}$ (blue) measurements over time during the tests.

(A) Ringer's only. (B) Voluven only. (C) Starch first, then Ringer's. Thick black lines indicate the duration of the infusions. Note that the decrease in $\mathrm{SpHb}$ when starting the Ringer's infusion in $(\mathrm{C})$ resembles the one seen in (A).

\section{Fig. 3.}

Bland-Altman plots showing the agreement between $\mathrm{SpHb}$ and $\mathrm{Hb}$ for all data sampling points in the three series of experiments: (A) Ringer's only. (B) Voluven only. (C) Starch first, then Ringer's.

\section{Fig. 4.}

The bias of the $\mathrm{SpHb}$ measurement versus the invasive $\mathrm{Hb}$ concentration for all data sampling points in the three series of experiments. The shaded areas illustrate a risk of misjudging $\mathrm{Hb}$ levels below $120\left(\mathrm{~g} \mathrm{l}^{-1}\right)$ by relying on $\mathrm{SpHb}$. The positive bias was greatest at low $\mathrm{Hb}$ levels.

\section{Fig. 5.}

(A) Lack of linear correlation between the perfusion index and invasive $\mathrm{Hb}$.

(B) Statistically significant linear correlation between the perfusion index and $\mathrm{SpHb}$. In both plots, $N=956$. 


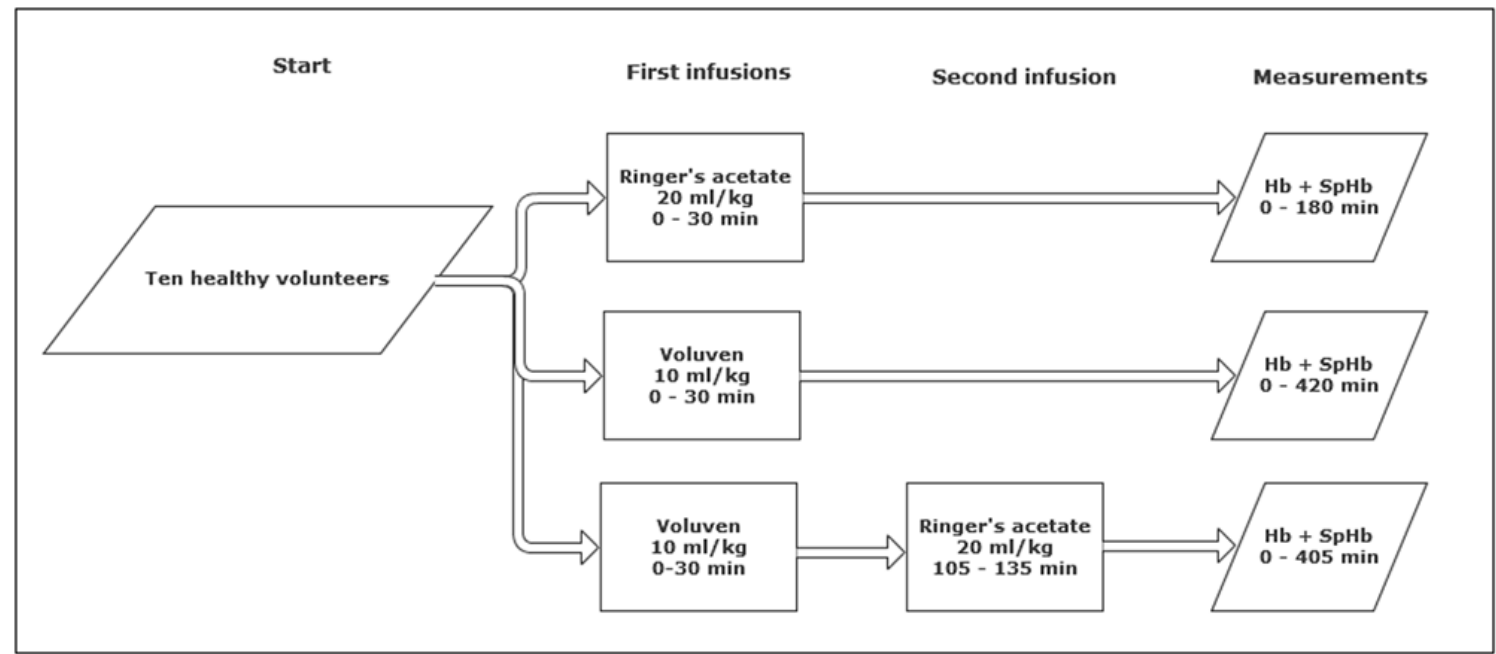

Fig. 1. 


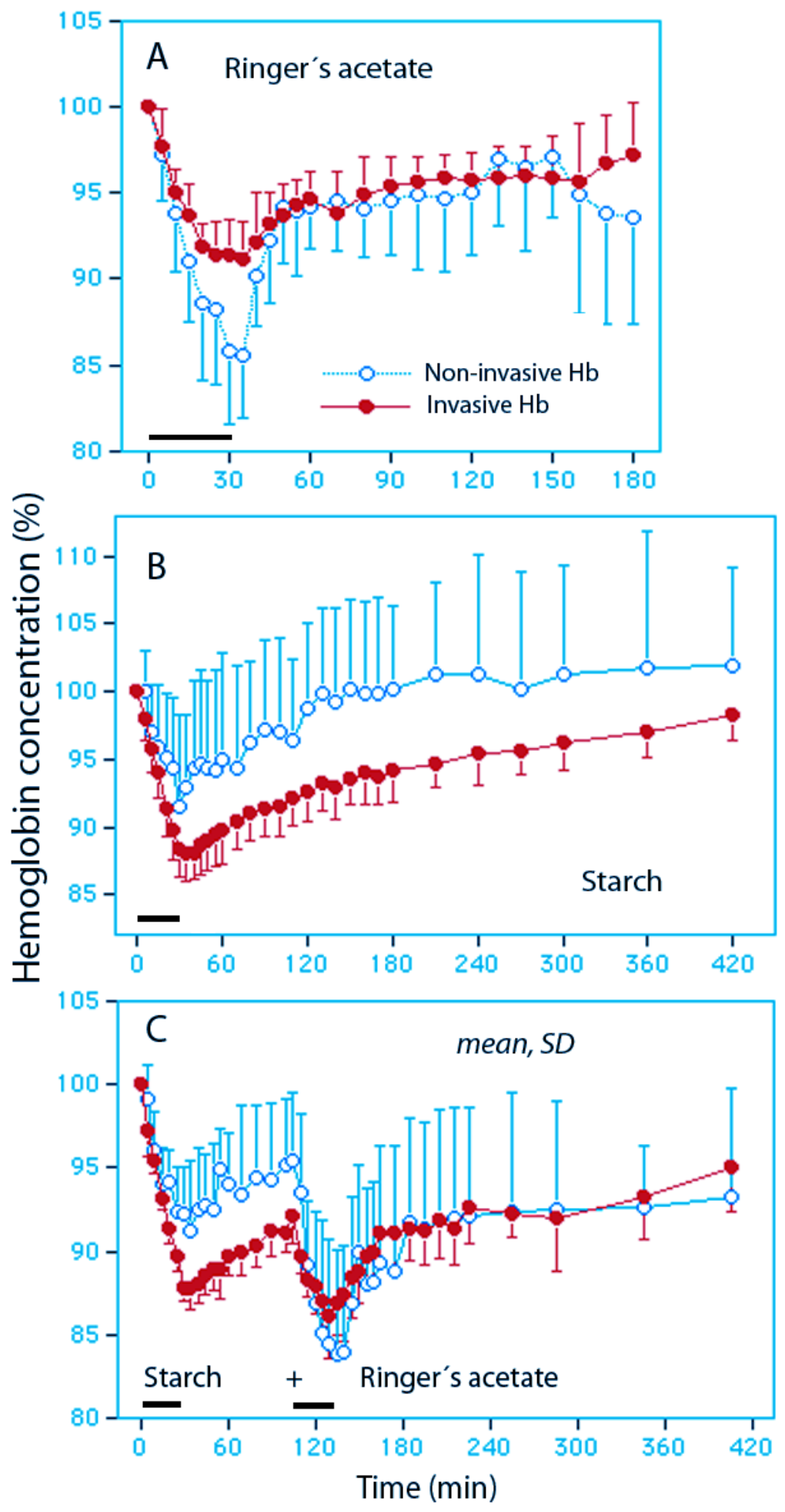

Fig. 2. 


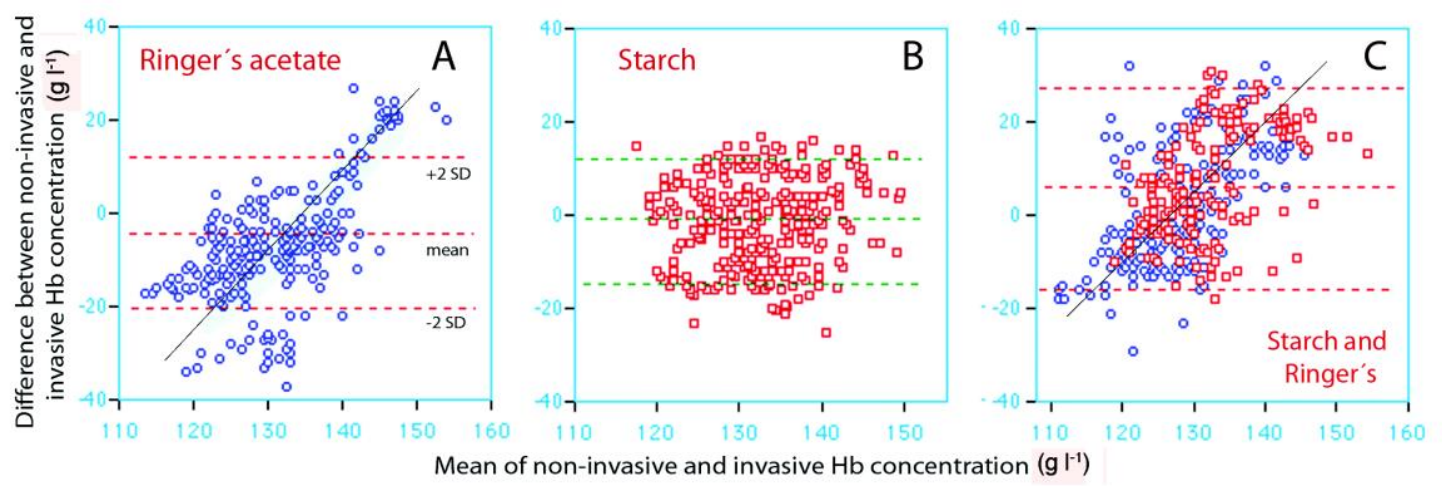

Fig. 3.
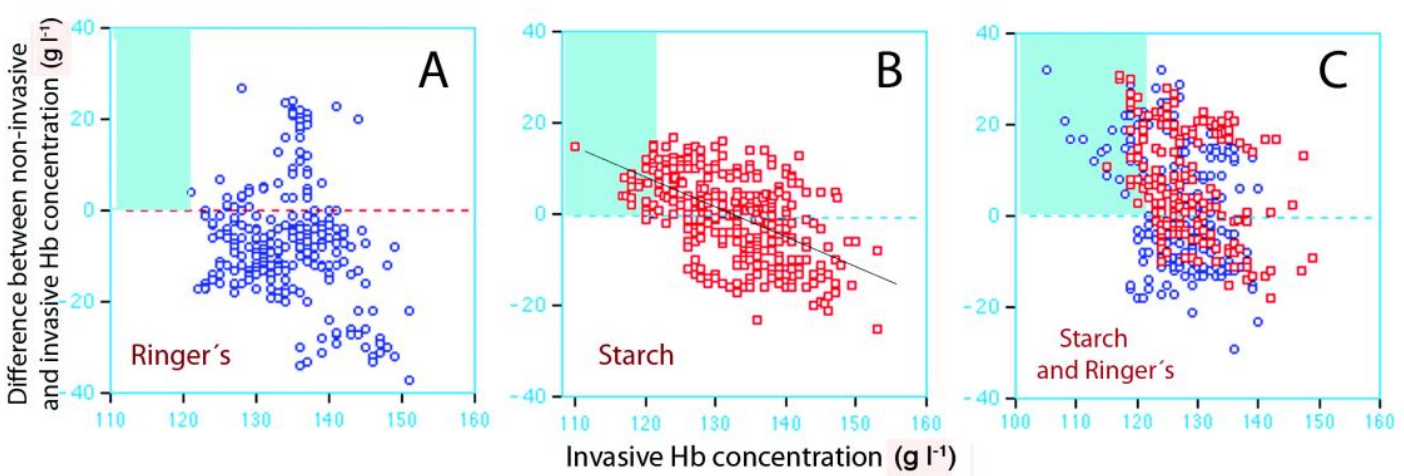

Fig. 4. 

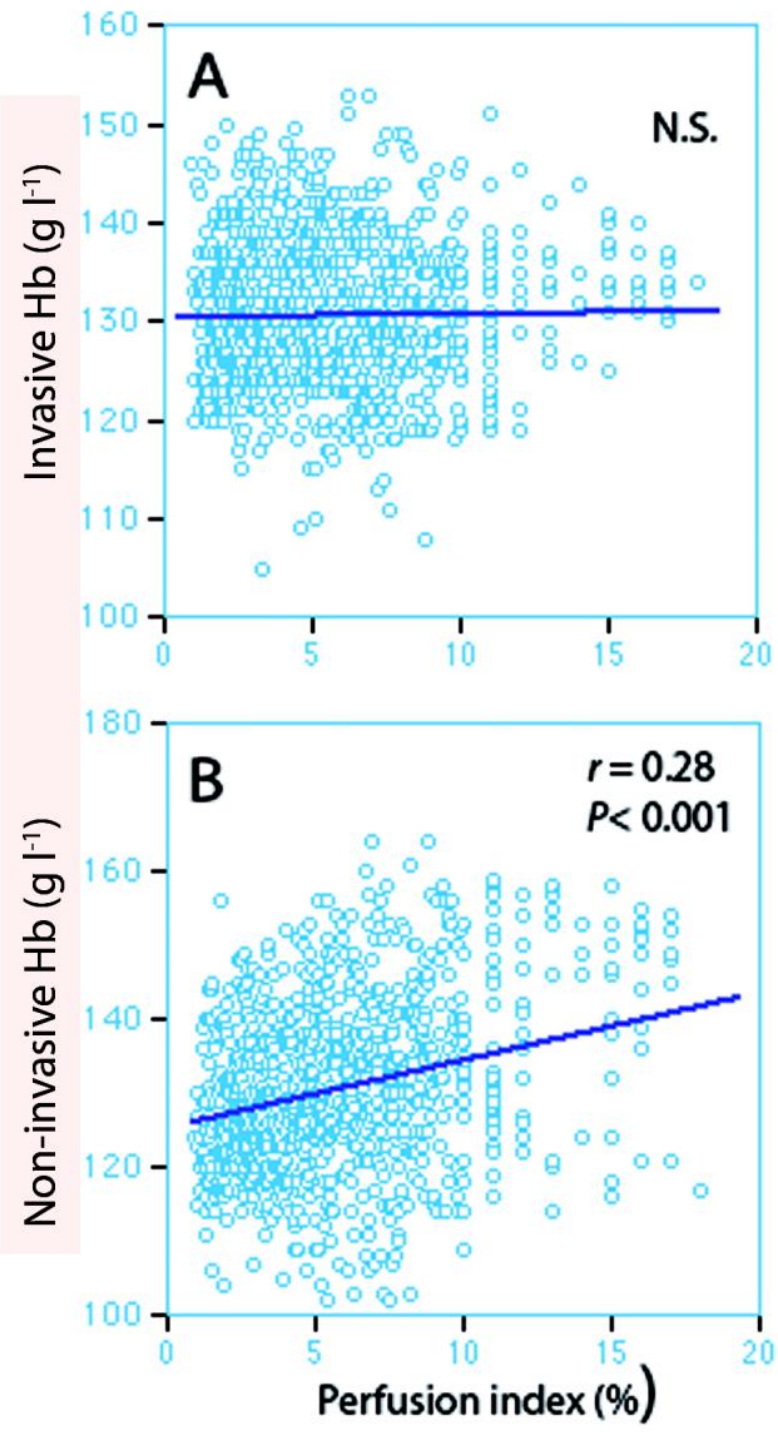

Fig. 5. 